\title{
Colonoscopic Removal of an Intrauterine Device That Had Perforated the Rectosigmoid Colon
}

\author{
Jin Myeong Huh ${ }^{1}$, Ki Seok Kim, Yong Seok Cho ${ }^{1}$, Dong Kwon Suh¹, Jae Uk Lee ${ }^{2}$, Seong Deuk Baek², \\ Sin Kil Moon ${ }^{2}$ \\ Departments of ${ }^{1}$ General Surgery and ${ }^{2}$ Internal Medicine, SM Christianity Hospital, Pohang, Korea
}

The intrauterine device (IUD) is a widely used contraceptive method. One of the most serious and rare complications of using an IUD is colon perforation. We report a case of colonoscopic removal of an IUD that had perforated into the rectosigmoid colon in a 42-year-old woman who presented with no symptoms. Colonoscopy showed that the IUD had penetrated into rectosigmoid colon wall and that an arm of the IUD was embedded in the colon wall. We were able to remove the IUD easily by using colonoscopy. The endoscopic approach may be considered the first choice therapy for selected patients.

\section{Keywords: Intrauterine device; Colon; Perforation; Colonoscopy}

\section{INTRODUCTION}

The intrauterine device (IUD) is a widely used contraceptive. However, it can cause uterine perforation, which is a rare, but serious complication. Migration of the IUD into the abdominal cavity and adjacent organs may cause abscess formation, obstruction, perforation, or fistulae. Methods for removal of migrated IUDs have been reported as endoscopy, laparoscopy, or laparotomy. We report a case of colonoscopic removal of an IUD that had perforated into the rectosigmoid colon.

\section{CASE REPORT}

A 42-year-old woman had an IUD inserted 18 months after her first pregnancy. Despite the insertion of the IUD, she became pregnant and gave birth to a child. After having delivered the 2 nd

Received: April 27, 2017 - Accepted: October 30, 2017

Correspondence to: Dong Kwon Suh, M.D.

Division of Coloproctology, Department of General Surgery, SM Christianity Hospita, 351 Poscodaero, Nam-gu, Pohang 37816, Korea

Tel: +82-54-289-1712, Fax: +82-54-275-0003

E-mail: gs3249@naver.com

ORCID code: https://orcid.org/0000-0002-7346-0476

(C) 2018 The Korean Society of Coloproctology

This is an open-access article distributed under the terms of the Creative Commons Attribution NonCommercial License (http://creativecommons.org/licenses/by-nc/4.0) which permits unrestricted noncommercial use, distribution, and reproduction in any medium, provided the original work is properly cited. baby, she had another IUD inserted, without knowing that the first IUD had migrated. She was asymptomatic for 14 years. Recently, she underwent a colonoscopy for a medical checkup at a private clinic, and a foreign body was found in her rectosigmoid colon. She visited our gynecology outpatient clinic. She had had 2 IUDs inserted. The gynecologist removed one, so only one should still be present when she visited the Department of Surgery. An abdominal X-ray and abdominal computed tomography (CT) were performed and showed that the IUD had partly migrated into the rectosigmoid colon and partly into the pelvic cavity (Fig. 1). Other laboratory tests were within normal range.

The patient consented to colonoscopic removal of the IUD, with the possibility of a laparoscopic removal. Before performing the laparoscopic procedure, we tried to remove the IUD using colonoscopy. Colonoscopy with cap was done under sedation with propofol. Colonoscopy showed an IUD that had perforated the rectosigmoid colon (Fig. 2). The stem of device was grasped with biopsy forceps and pushed in a proximal direction. The device was easily removed. After removal of the IUD, granulation tissue existed around the perforation site, and the surrounding mucosa was relatively healthy. Endoscopic closure of the wound was performed using hemoclips to prevent leakage. The patient tolerated the procedure well. After the procedure, she was kept fasting for 24 hours. She took a soft diet after 48 hours and was discharged 4 days later without any complications. 

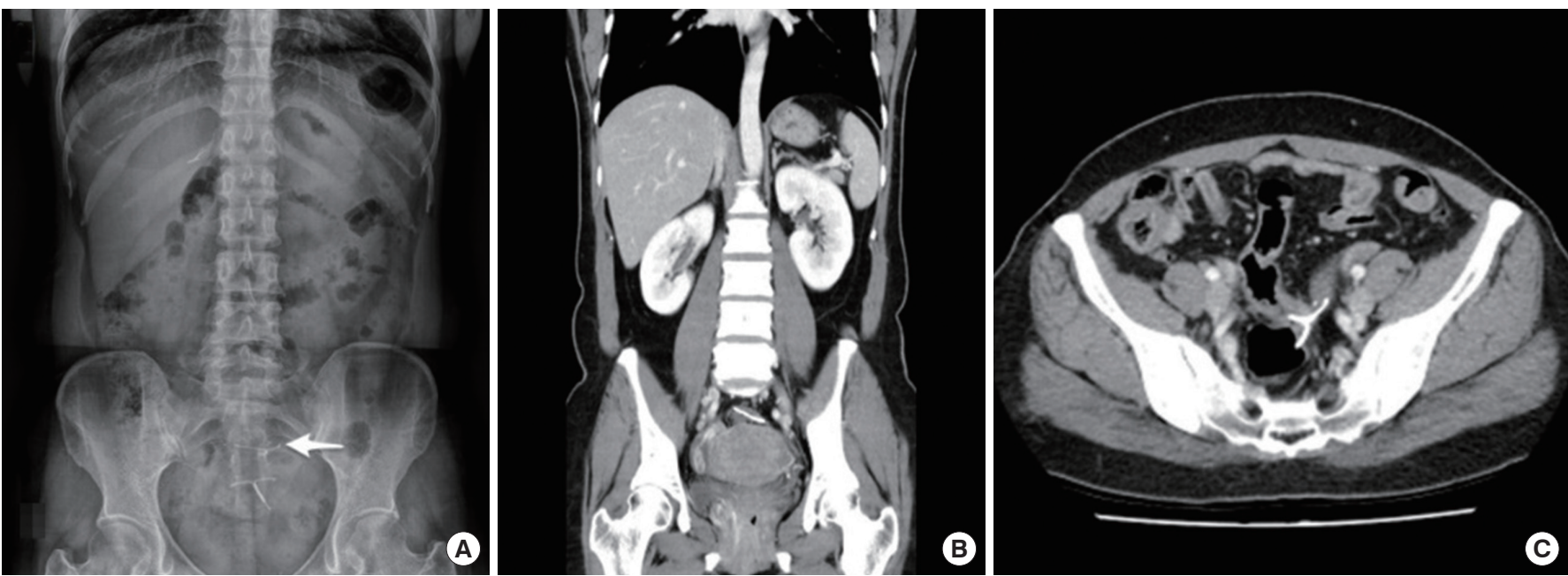

Fig. 1. Simple abdominal X-ray and computed tomography (CT) scan findings: (A) simple abdominal X-ray showing the migrated intrauterine device (arrow), (B) coronal CT scan showing the extrauterine position of the contraceptive device posterior to the uterus and in the rectosigmoid colon, and (C) axial CT scan showing the extra-uterine position of the stem of the contraceptive device within the rectosigmoid colon after having perforated the uterus.
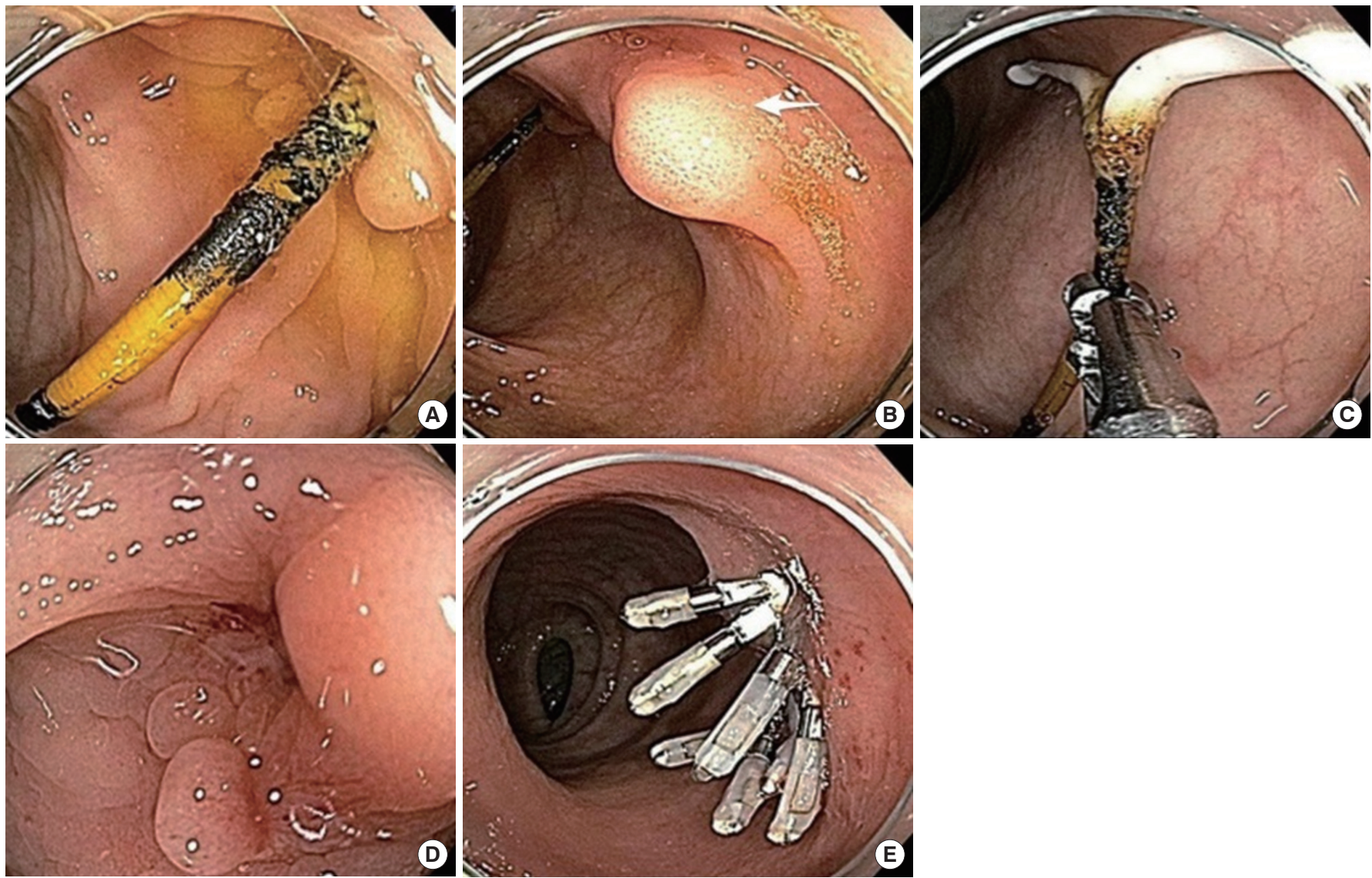

Fig. 2. Colonoscopic findings: (A) an intrauterine device (IUD) penetrating the rectosigmoid colon wall with surrounding granulation tissue, (B) an arm of the IUD embedded in the colon wall (arrow), (C) the IUD being removed by using biopsy forceps, (D) the wound site after the IUD had been removed, (E) hemoclips at the wound site to prevent perforation of the colon. 


\section{DISCUSSION}

The IUD is a safe, effective and widely used contraceptive method. Uterine perforation is a rare, but serious, complication of using an IUD, and the incidence of uterine perforation is estimated to be 1.3/1,000 [1]. Uterine perforation is generally asymptomatic, but may cause abdominal pain, diarrhea, and fever if bowel injury is present. Migration of an IUD into adjacent organs and structures can cause obstruction, perforation, ischemia, mesentery injury, strictures, and fistulae [2]. When migration of an IUD is suspected, a simple abdominal X-ray will help rule out displacement of the IUD. A CT scan may be used to determine the exact location of the device and its relation to adjacent organs.

The World Health Organization recommends that all migrating IUDs be removed, as there is a risk of injury to adjacent organs and structures and inflammatory reactions [3]. Methods for removing IUDs that have perforated surrounding tissues include endoscopic methods, laparoscopic methods, and a laparotomy. The way in which the IUD is removed depends on the location of the device and the degree of involvement with other organs. Thanks to the development of laparoscopic instruments and techniques, laparoscopic surgery has replaced the laparotomy and has become the first choice of treatment for the removal of migrated IUDs. However, in the case of severe adhesions and bowel perforation, the possibility of conversion to a laparotomy is high, and the conversion rate to a laparotomy was reported as $34.6 \%[4,5]$. When the IUD is in the lumen of the bowel or in the retroperitoneal area, a laparoscopic approach is likely to fail because the IUD is not visible.

A few reports have been published on the sigmoidoscopic or colonoscopic removal of an IUD perforated into the colon [6-9]. When the IUD is located within the colon wall, colonoscopy is useful for removing the IUD, and most patients do not develop peritonitis after removal of an IUD by using colonoscopy. The possible ways of removing a perforating IUD have been gradually increasing in number due to the development of endoscopic instruments and techniques. Reports have been published on the successful endoscopic removal of an IUD by using a needle knife sphincterotomy of an IUD embedded in the colon wall or by a gradual pulling of an IUD fixed in the rectum by using a rubber band through the endoscope $[8,9]$. However, when the device is firmly embedded in adjacent structures, colonoscopic removal is not suitable.

In summary, uterine perforation by an IUD is an uncommon complication. Removal of the IUD is recommended due to the risk of injury to adjacent organs and to associated inflammatory reactions. In our case, colonoscopy showed that the IUD had penetrated the rectosigmoid colon wall and that an arm of the IUD was embedded in the colon wall. We were able to remove the IUD easily by using colonoscopy. These results show that after appropriate patient selection and surgical preplanning, an endoscopic approach can be tried as the first treatment for a perforating IUD, thereby avoiding unnecessary surgery.

\section{CONFLICT OF INTEREST}

No potential conflict of interest relevant to this article was reported.

\section{REFERENCES}

1. Andersson K, Ryde-Blomqvist E, Lindell K, Odlind V, Milsom I. Perforations with intrauterine devices. Report from a Swedish survey. Contraception 1998;57:251-5.

2. Arslan A, Kanat-Pektas M, Yesilyurt H, Bilge U. Colon penetration by a copper intrauterine device: a case report with literature review. Arch Gynecol Obstet 2009;279:395-7.

3. World Health Organization. Mechanism of action, safety and efficacy of intrauterine device (WHO Technical Report Series No.753). Geneva (Switzerland): World Health Organization; 1987.

4. Gill RS, Mok D, Hudson M, Shi X, Birch DW, Karmali S. Laparoscopic removal of an intra-abdominal intrauterine device: case and systematic review. Contraception 2012;85:15-8.

5. Demir SC, Cetin MT, Ucünsak IF, Atay Y, Toksöz L, Kadayifçi O. Removal of intra-abdominal intrauterine device by laparoscopy. Eur J Contracept Reprod Health Care 2002;7:20-3.

6. McCombie JJ, Le Fur R. Colonoscopic removal of an ectopic intrauterine device. ANZ J Surg 2012;82:369-70.

7. Ma GW, Yuen A, Vlachou PA, de Montbrun S. An unconventional therapeutic approach to a migratory IUD causing perforation of the rectum. J Surg Case Rep 2016 Feb 2;2016(2). pii: rjw004. https://doi.org/10.1093/jscr/rjw004.

8. Gonenc M, Kalayci MU, Turhan AN, Deniztas C, Alis H. Endoscopic treatment of a transmigrated intrauterine device to colonic wall: a case report. Am J Obstet Gynecol 2011;204:e3-5.

9. Toprak E, Göktürk HS, Tolu A. A new technique for the removal of a transmigrated intrauterine device with rectum penetration. Turk J Gastroenterol 2015;26:82-4. 